法所获得的結果，在成功率及生长率上，都无显著 差別。但就方法本身来說，飼养层法較为复杂，需 望考虑的因素較多，而且易于引起污染。

中国科学院实驗生物研究所 腫瘁研究室組織培养組

\section{深降溫时阻断头部血流对 脑功能的影响}

目前临床上常用的降溫麻醉是将体溫降至 $30^{\circ} \mathrm{C}$ 左右，这时可容呚阻断全身循环 5 至 7 分鈡来进行 心脏手木，手术后不致影响脑功能的恢复。然而这 短短几分鈡的安全时限对施行較复杂的心胜內手术 就丵不足了，因此寻求延长手术时限的方法是当前 医学界的重要問題。近年来有关深降溫的䂰究逐潮 开展起来，Niazi 等 [1,2] Drew 等 ${ }^{[3]}$ 分別在狗、猴 和病人身上进行了覌察。本文就深降温时脑耐受缺 血能力的問題进行了研究。

用狗作为实驗动物。考虑到体溫过低会导致心 室頙动症，因此朵用头部单独降㯰法，使脑溫降至 $20^{\circ} \mathrm{C}$ 以下，再阻断头部血循环，这样来覌察大脑功 能在长期缺血后的快复情况。实驗时，将狗用戊 巴比努鈵麻醉，快速地施行 Benetato 氏隔离头手 术 ${ }^{[4]}$ 。为了滅少中枢缺血对心脏机能的抑制作用， 将两側迷走交威吩經千切断。降溫前記录动物頂、 枕部的脑电图，抹測定皮层、食道下段和直腸温 度。降温是用 $2^{\circ} \mathrm{C}$ 冰水冾却两側项动脉和头 砟 表 面，同时用热水袋在躯干部保溫。大約經过一小时 待脑溫降至 $20^{\circ} \mathrm{C}$ 左右, 垖行阻断两側頸动脉血流。 脑电图于阻断血流后 1 分鈡內就变成平綫。这时候 脑溫下降的速度也加快，然后使脑溫維持在 $15^{\circ} \mathrm{C}$ 左右，其时脑皮层下溫度的为 $20^{\circ} \mathrm{C}$ ，而食道、直腸 溫度都在 $30^{\circ} \mathrm{C}$ 以上，投且逐步上升。阻断血流 45 至 90 分鈡后，恢复头部循环，脑溫在牛小时內就 上升到 $30^{\circ} \mathrm{C}$ 以上。有关动物的脑电变化和各种神 桱反射活动的恢复情况，簡迅于下:

在彻底阻断头部血流的 9 次实驗中，1例阻断 血流 46 分鈡， 3 例阻断 60 分鈡，5例 阻断 90 分 鈡，覌察到所有动物的脑电活动都在恢复血 流 后 1一2小时就开始出現，表現为低幅的不規則慢波; 3
至 5 小时,振幅、頻率都显著增高,接近降溫前水平; 6 小时以后脑电图上出現快频的低幅波，这是由于 动物已处在非腋醉状态。此外,各种神經反射活动都 能在 2 小时內恢复过来。它們出現的程序是: 呼吸 运动恢复最早,不到牛小时,有的只有 5 分鈡; 瞙孔 对光反应次之; 角膜反射和睑睷反射約在 1 小时左 右就先后恢复，个別的例子也有延至 2 小时才恢复 的。虽然有 2 例在复溫后 3 小时死于心力 毫 竭, 但动物的脑电波和各种反射活动在死亡前都已出現 了。一般說来凡阻断血流时間越短的动物，上迌脑 功能的恢复也越早。

实驗表明: 大脑在深降溫时（皮层溫度 $15^{\circ} \mathrm{C}$ 、 皮层下溫度 $20^{\circ} \mathrm{C}$ ) 能耐受缺血至 90 分鈡，不致影 响上述脑功能的恢复。

此外，在多次实驗中覌察到，单用冰水在头頣 表面降溫也能使动物脑皮层溫度接近 $20^{\circ} \mathrm{C}$ ，同时躯 干保溫使体溫維持在 $30^{\circ} \mathrm{C}$ 左右，其时除呼吸減綏 外，血压、心率、心电图等都无显著变化。因此， 我們設想,在不影响心脏机能的前提下,如果临床上 施行体表降溫的同时，輔以头部降温，无疑地将 增强脑对缺血的耐受力，可以适当地延长手术的安 全时限，至少可以防止某些超越安全时限的手术意 外。

\section{江振裕 王泰安 傅度寿} （中国科学院生理研究所）

[1] Niazi, S. A., Lewis, F. J., Surg. Gyn. Obst., 1956, 102, 98-106.

[2] Niazi, S. A., Lewis, F. J., Ann. Surg., 1958, 147, 264.

[3] Drew, C. E., Anderson, J. M., Lancet, 1959, 1, 748.

[ 4 ] Benetato, G. R., Opriscu, C. et Baciu, J. J. de Physiol., 1956, 48, 1131-1140.

\section{溴芳乙銨对交感神經末梢 介体释放的影响}

澳苳乙鉸（Brobenetium）是一种新型降压䓎， 国外称 Darentine 或 Bretylium tosylate，其結构如 下: 


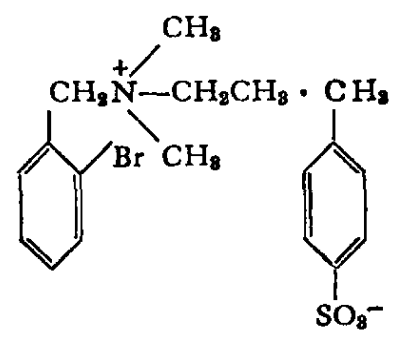

据称此获对交感神經末梢具有高度的选择性，能抑 制末梢的介体释放从而产生降压作用，抹且在抑制 介体释放的浓度下，对神經节和副交感神經末梢无 明显作用; 但其抑制交憾斾經末梢释放介体的作 用，侣无直接证明。为了探求澳苠乙鉸对交感神經 末梢介体释放的作用，我們进行了实驗，現将实驗 情况簡介如下:

实驗是依下迅方法进行：利用离体鬼耳灌流， 刺激冤耳耳大神經(交感)，再把灌流流出液直接滴 于鳮自腸上，以測定刺激耳大神經时是否有介体释 放。若有介体释放，鳮盲腸接触灌流液后应迅速松 弛。免耳灌流的区力为 40 毫米水柱，营养液是台 氏液，其中含 $0.01 \% \mathrm{KCl}$, 水浴溫度为 $40^{\circ} \mathrm{C}$, 鳮盲 腸的水浴溫度保持在 $37.5-38.5^{\circ} \mathrm{C}$ ，离体免耳灌 流的流出液直接滴于制备好的鸡盲晹上，后者抹不 放入台氏液中，其营养靠免耳流出液維持，其收縮 直接記录在紋鼓上。

在刺激免耳耳大神經前，将 0.1 毫升的 $1: 10^{-7}$ 盐酸堅上腺素，直接加入滴于鸡盲腸的灌流液中， 来測定观盲腸标本的反应性是否良好，抹重复数 次，俟其民应恒定后，以感应电刺激（6 厘米每次 刺激一分鈡) 离体免耳耳大神經，脷看鳮盲腸的活 动有何改变。第一次刺激耳大神經后，隔 15 分鈡 再重复一头。应注意的是，刺激冤耳耳大神經时， 引起血管收縮，而流出滴数显著減少，致使鳮盲腸 往往发生强梨的收縮。因此，当滴数減少时，应开 放另一盛有正常(溫度相同的)灌流液系統，滴入鳮 盲腸，維持滴数的基本惿定 (图 $1 \mathrm{~A}$ )。在此情况 下，可以覌察到与腎上腺素相似的效应。得到效应

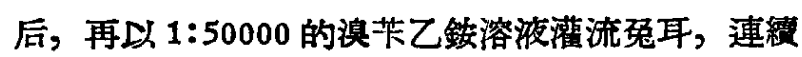
灌流 20 分鈡，此时由愁耳流出的灌流液不应接触 鳮盲腸，而后者应以正常灌流液来滴定营养。用澳 茉乙鉸溶液灌流 20 分鈡后, 改用正常灌流液冲洗孕
耳 10 分鈡，再把从免耳流出的濩流液直接滴于 盲腸上，然后用上迅浓度的盐酸㹂上腺素以确定偶 盲腸标本的反应良好,再刺激耳大神經,覌察其对洮 盲腸的影响。
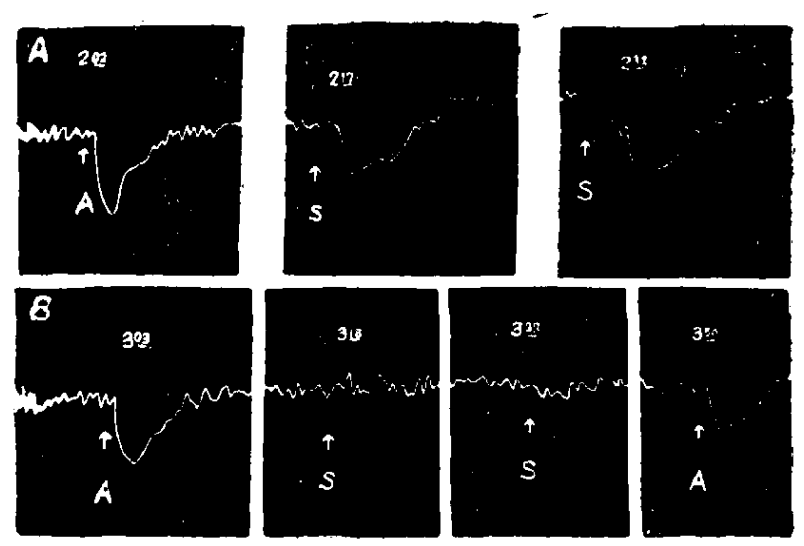

图 1 离体揊直腸对腎上腺素和电刺激离体杂耳 耳大神經时灌流流出液的反应

$A$, 給萂前

A：腎上腺素 $1: 10^{-7}, 0.1$ 毫升对恤直晹 作用(对炤)

S: 感应电刺激 (6 厘米每次一分鈰)离体

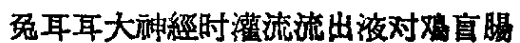
的作用。

B，漟苠乙銨 $1: 50000$ 灌流离体忽耳 20 分鈡后

A：堅上腺素 $1: 10^{-7}, 0.1$ 毫升对观目晹 作用(对照)

S: 再刺激离体㭆耳耳大神經时灌流液对 揊首腸的作用。

在我們的实驗条件下，灌流澳苠乙鉸后，刺激 离体免耳耳大神經，扭不能引起鳮盲腸的弛䜌（图 1 B)。經过多次重复，結果完全一致，因此，可以 副为，滇苠乙鉸确能抑制交感动經末梢释放介体。

本实驗是在张昌紹敉授指导下进行的，扑冰上 海医获工业研究所合成药室供給澳苠乙 銤，媌 此 志謝。

\section{裴印权 方文龍*}

(上海第一医学院莉理教研粗)

\footnotetext{
*延边医学院进修教师。
} 